\title{
DESENVOLVIMENTO DE UM TERMO DE REFERÊNCIA PARA O GERENCIAMENTO DE PROJETOS INTEGRADOS EM UMA INSTITUIÇÃO PÚBLICA
}

\author{
Development of a Reference Model to Integrated Design Management on \\ Public Institutions
}

Paulo Roberto ANDERY' e-mail|CV Lattes

Cintia CAMPOS ${ }^{i i}$ e-mail| CV Lattes

Eduardo Marques ARANTES ${ }^{\text {iii }} \mathrm{e}-\mathrm{mail}$ | CV Lattes

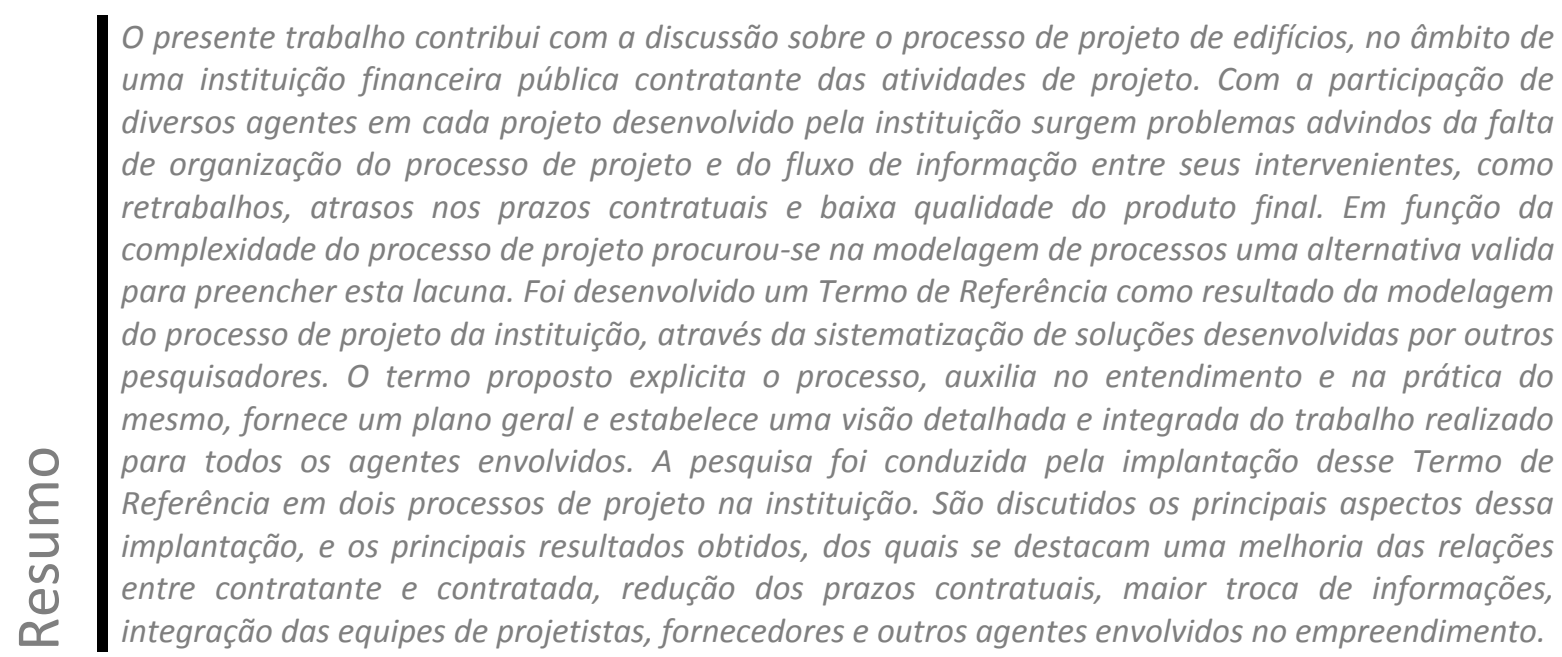

Palavras-chave: Processo de projeto em instituições públicas, modelo de referência, projeto simultâneo.

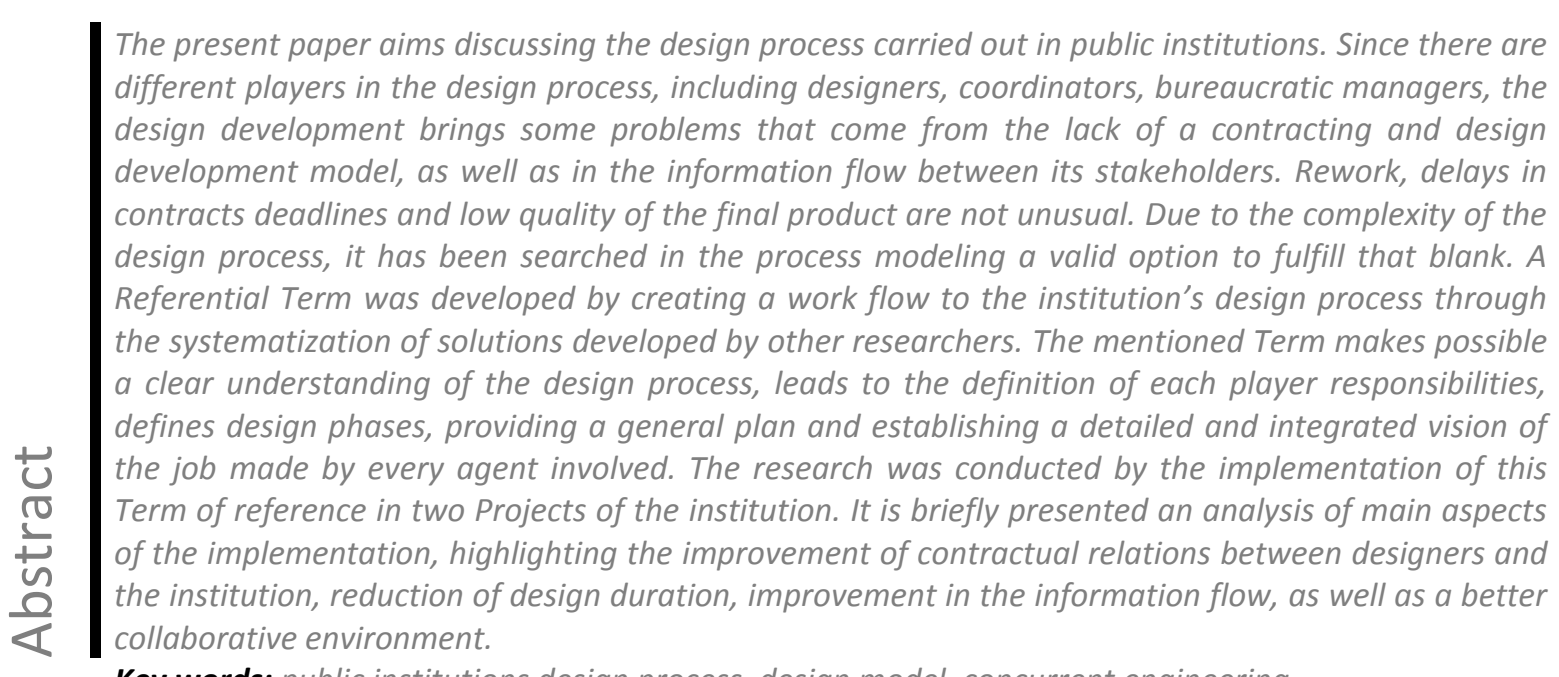

Key words: public institutions design process, design model, concurrent engineering 


\section{INTRODUÇÃO}

O processo de projeto é uma etapa estratégica do empreendimento com relação aos gastos de produção e a inserção de qualidade ao produto. 0 projeto tem a capacidade de subsidiar as atividades de produção em canteiro de obras com informações detalhadas e que não poderiam ser igualmente geradas no ambiente da obra. A partir de um projeto completo, detalhado para a obra, torna-se possível elaborar um planejamento e uma programação mais eficientes, assim como um programa efetivo de controle da qualidade para materiais e serviços.

O projeto pode ser entendido como produto e como processo. 0 projeto como "produto" traduz requisitos dos clientes em representações gráficas e especificações técnicas determinando toda a visualização e materialização do produto edifício que será gerado e, como "processo", compreende atividades distintas e coordenadas que focam também as etapas de execução das edificações (FABRÍCIO 2002; ANDERY et al. 2004).

Um maior cuidado com a etapa de projeto repercute em ganhos, e o investimento envolvido é relativamente modesto comparado aos gastos com modificações durante a execução. As etapas de projeto são passíveis de revisões, pois são feitas no "papel" e existem possibilidades de intervir e de agregar qualidade ao longo das etapas subseqüentes que podem possuir custo elevado relativo às mudanças na fase de projeto (MELHADO, 1994).

Nessa direção "O processo de Projeto envolve todas as decisões e formulações que visam subsidiar a criação e a produção de um empreendimento, indo da montagem da operação imobiliária, passando pela formulação do programa de necessidades e do projeto do produto até o desenvolvimento da produção, o projeto "as built" e a avaliação da satisfação dos usuários como o produto. Por esse critério o processo de projeto engloba não só os projetos de especialidades de produto, mas também a formulação de um negócio, a seleção de um terreno, o desenvolvimento de um programa de necessidades, bem como o detalhamento dos métodos construtivos através de projetos para produção e o planejamento da obra. E os agentes da concepção e do projeto do empreendimento são os projetistas de arquitetura e engenharia e todos aqueles que tomam decisões relativas à montagem do empreendimento" (FABRÍCIO, 2002)
Com a participação de diversos agentes no processo de projeto surge a necessidade de uma organização competente do fluxo de informação entre os agentes e uma gestão competente das interfaces de projeto (OLIVEIRA, 1999).

Segundo FABRÍCIO (2002) "no processo tradicional seqüencial essas interfaces ocorrem preponderantemente de maneira unidirecional, ou seja, após a formulação ou concepção de um aspecto do projeto do empreendimento as informações geradas são transmitidas e são o ponto de partida para a etapa seguinte." Assim, é preciso planejar o processo de projeto com mais cuidado e, principalmente, respeitar a essência deste processo que é a interatividade.

As deficiências de integração e de troca de informações entre os projetistas e demais agentes envolvidos no processo precisam ser combatidas por sistemas de informação eficientes e, por isso, ganha força a utilização de meios eletrônicos (e-mail, intranet, extranet, internet, etc.) como ferramentas de comunicação e troca de informações, refletindo uma tendência de utilização crescente de redes de informações na gestão de projetos.

0 principal mecanismo que vem sendo utilizado para viabilizar a colaboração digital no processo de projeto são as extranets ${ }^{1}$ que permitem compartilhar bases de dados digitais entre diferentes projetistas, eliminando a necessidade de trocas de projetos em papel ou via e-mail (MELHADO, S. et al, 2005).

De acordo como Vargas (2000), boa parte dos projetos não atinge o resultado esperado, em decorrência das chamadas falhas gerenciais. Segundo este autor as falhas acontecem quando há pouca compreensão da complexidade do projeto; o projeto inclui muitas atividades e pouco tempo para realizá-las; as estimativas financeiras são pobres e incompletas; o projeto é baseado em dados insuficientes, ou inadequados; o sistema de controle é inadequado; o projeto não teve um gerente de projeto ou teve vários; não foi destinado tempo para as estimativas e o planejamento; não se conheciam as necessidades de pessoal, equipamentos e materiais; fracassou a integração dos elementos chaves do projeto;

${ }^{1}$ As extranets consistem na compra de um espaço na memória de um servidor remoto para o armazenamento centralizado de arquivos e informações de projeto, bem como a assinatura de um serviço informatizado de auxílio ao gerenciamento de equipes de projeto e trocas de informação (Melhado, S. et al, 2004). 
cliente e projeto tinham expectativas distintas e, muitas vezes, opostas; as pessoas não estavam trabalhando nos mesmos padrões, ou os padrões de trabalho não foram estabelecidos. Em última análise, o autor reafirma a idéia da necessidade de aprimorar o sistema de contratação e desenvolvimento do processo de projeto como conditio sine qua non para que sejam atingidos os objetivos de um empreendimento.

Os empreendimentos de construção têm como característica o caráter seqüencial das intervenções para cada um dos seus participantes. Mudanças vêm sendo introduzidas para aperfeiçoar o processo de projeto, na tentativa de romper o paradigma do modelo seqüencial de desenvolvimento de produto e de estimular uma visão abrangente e integrada do binômio projeto/produção, com vistas a reduzir prazos e custos, aumentar a qualidade e a satisfação de todos os envolvidos.

Uma das propostas de mudança presente na literatura é a utilização da filosofia conhecida como Engenharia Simultânea (concurrent engineering) 2. A Engenharia Simultânea é uma alternativa trabalhada em setores de produção seriada. $\mathrm{Na}$ análise do processo de projeto de edificações no Brasil é significativo o trabalho de FABRÍCIO (2002), particularmente na tese Projeto Simultâneo na Construção de Edifícios". O Projeto Simultâneo tem conseguido, através de atividades paralelas, o encurtamento do tempo global de desenvolvimento do produto e a diminuição de problemas decorrentes do projeto, com uma maior interação entre todos os agentes envolvidos.

De acordo com MELHADO (1999) "o conceito de projeto simultâneo inclui a consideração antecipada e global das repercussões das decisões de projeto face à eficiência dos processos produtivos e à qualidade dos produtos gerados, levando em conta aspectos como construtibilidade, habitabilidade, manutenabilidade e sustentabilidade das edificações."

Neste contexto, o desenvolvimento simultâneo do projeto deve buscar organizar o processo de projeto em acordo com a lógica intelectual de desenvolvimento de projetos e valorizar a atuação conjunta e coordenada dos diferentes profissionais e interesses envolvidos.

O modelo de Projeto Simultâneo indaga algumas questões importantes:

“Como a equipe de projeto desenvolverá dado produto, cumprindo os prazos determinados, obtendo a qualidade desejada e mantendo os custos dentro de parâmetros aceitáveis?

Como a equipe de projeto deverá ser constituída e deverá relacionar-se para desenvolver o produto, levando em conta as restrições de resolução e de solução?

E, como a equipe de projeto conduzirá suas atividades desde a identificação do problema até a documentação final dos produtos, sendo eficiente e eficaz em seus resultados?" (ROMANO, 2003).

Em última análise, busca-se a implementação de um sistema de gestão do processo de projeto que faça parte de um sistema mais geral de gerenciamento dos empreendimentos, priorizando a integração entre as etapas de projeto, execução e operação das edificações, empregando um conceito que mais recentemente vem sendo dominado Integrated Design and Delivery Solutions (PRINS e OWENS, 2010).

Segundo FABRÍCIO (2002), de modo geral, na área projetual, serviços de engenharia são desenvolvidos por profissionais e empresas contratadas para prestar consultoria ou desenvolver o projeto de determinada especialidade. Diante do exposto ressalta-se que as empresas do Poder Público contratam projetos de profissionais que pertencem a distintas organizações, apresentando diferentes formas de trabalho, experiência e formação. Estes profissionais não possuem o hábito de trabalhar de forma integrada apresentam, dessa forma, dificuldades de comunicação e entendimento do escopo de serviços, tendo como conseqüência incompatibilidades e retrabalho.

Em função da complexidade do processo de projeto há modelos que podem ser abordados e aprofundados. Dentre estes, destaca-se a elaboração de modelos de referência que buscam melhorias no processo de projeto.

Para solucionar estas questões, foi proposto por ROMANO (2003) um Modelo de Referência para o Gerenciamento do Processo de Projeto Integrado de Edificações (GPPIE). Parte da estrutura deste modelo será adotada, no presente trabalho, como referência para o desenvolvimento de uma proposta para uma instituição pública. Na mesma direção os Manuais de Escopo desenvolvidos pelas entidades mais representativas da construção imobiliária (ASBEA, SINDUSCON, ABECE, 
ABRASIP, ABRAVA, AGESC e outros) subsidiarão a construção deste trabalho3.

A modelagem de processos, segundo ROMANO (2003) consiste em um conjunto de atividades a serem seguidas para a criação de um ou mais modelos de algum processo para atender os propósitos de representação, comunicação, análise, síntese, tomada de decisão ou controle. Ainda de acordo com ROMANO (2003),o propósito de um modelo de referência é de explicitar os processos, auxiliando no entendimento e na prática dos mesmos, permitindo a compreensão das informações do ciclo de vida do produto, bem como do emprego integrado de métodos e ferramentas de auxílio ao projeto $\mathrm{e}$ ao seu gerenciamento $\mathrm{e}$, estabelecendo uma visão detalhada e integrada do trabalho realizado.

0 modelo do processo de projeto busca fornecer um plano geral que visa diminuir ou evitar problemas relacionados à falta de planejamento do processo. (TZORTZOPOULOS, 1999).

0 Termo de Referência, desenvolvido através da modelagem do processo, por meio da identificação dos objetivos e características dos processos sob a responsabilidade dos contratantes, possibilita visualizar o que a empresa que contrata e promove o desenvolvimento de projeto de edificações deve prover e precisa receber e a forma com que deve relacionar com os seus projetistas para que o processo de projeto se desenvolva com qualidade.

0 presente trabalho não aborda ferramentas de gestão de prazo, custos e comunicação. Delimitase no estudo do processo de projeto de edificações de uma instituição pública. Tem como objetivo principal melhorar o gerenciamento do processo de projeto de edificações em uma instituição pública contratante, através de um Termo de Referência para contratação de projetos, sistematizando soluções desenvolvidas por outros pesquisadores, na medida em que a instituição pesquisada não possui um modelo a ser seguido.

Fica claro que a proposição de um termo de referência para a contratação de projetos de per si não garantirá necessariamente a melhoria do processo de projeto e uma melhor integração entre projeto e obra. Torna-se necessário, além de estabelecer um modelo para a gestão do processo de projeto, considerar a dimensão social do projeto - a interação entre os agentes e ações que garantam a criação de um ambiente de colaboração -, bem como o adequado suporte tecnológico, quer seja por meio de ambientes colaborativos de projeto, quer seja pela gradual implementação de softwares que trabalham no conceito de Building Information Modelling (OWEN et al., 2010).

0 presente artigo apresentará a estrutura do trabalho, mas não apresentará o Termo desenvolvido com detalhes o que poderá ser verificado na dissertação Termo de Referência para o Gerenciamento de Projetos Integrados em uma Instituição Pública (CAMPOS, 2010).

Com base no diagnóstico da instituição, na análise da lei 8666 e em modelos de outros pesquisadores desenvolveu-se o Termo de Referência para a contratação de projetos. Especificamente procurou-se: instituição.

Registrar a prática de projeto da

- Incluir a definição das principais atividades a serem desenvolvidas, suas relações de precedência, a definição clara de papéis e responsabilidades dos principais intervenientes e do fluxo principal de informações do processo.

- $\quad$ Desenvolver um termo que sirva de guia para a empresa contratante padronizar a contratação, procurando: definir o escopo, estabelecer relações de precedência e esclarecer ao contratante o que contratar e exigir.

- Um indicador do processo de projeto.

Foram tomados como pressupostos obedecer às exigências legais da lei 8666 e desenvolver um termo de simples absorção e aplicação que alcance um desenvolvimento integrado e simultâneo.

${ }^{3}$ Os manuais de escopo são guias completos do que deve fazer parte dos projetos e qual o nível de detalhamento requerido. Estão disponíveis para consulta no site $<<$ HTTP://www.manuaisdeescopo.com.br $>$. Neste trabalho foram utilizados os manuais desenvolvidos para as áreas dos projetos de Arquitetura e Urbanismo, Estrutura, Sistemas Elétricos, Sistemas Hidráulicos e Ar condicionado e Ventilação. 


\section{METODOLOGIA}

O trabalho teve o caráter de pesquisa-ação. Foi caracterizado como um método de investigação de natureza qualitativa que procurou resolver problemas específicos, dentro de um grupo ou organização, respeitando diretrizes definidas. A pesquisa-ação tem por pressuposto que os sujeitos que nela se envolvem compõem um grupo com objetivos e metas comuns, interessados em um problema que emerge num dado contexto no qual atuam desempenhando papéis diversos. Constatado o problema, o papel do pesquisador consiste em ajudar o grupo a problematizá-lo, ou seja, situá-lo em um contexto teórico mais amplo e assim possibilitar a ampliação da consciência dos envolvidos, com vistas a planejar as formas de transformação das ações dos sujeitos e das práticas institucionais.

A pesquisa teve como objeto de estudouma instituição financeira pública, que possui um setor de engenharia bem estruturado, existente desde a criação da empresa, que é das mais antigas do país. Parte do processo de planejamento dos empreendimentos - nesta pesquisa caracterizados como agências bancárias - é bem estruturado, com etapas e procedimentos claramente definidos. Porém, a partir do momento em que os projetos são contratados no mercado (terceirizados), fica clara a falta de um fluxo de informações e rotinas

\section{TERMO DE REFERÊNCIA}

\subsection{Diretrizes para o Desenvolvimento do Termo de Referência na Instituição}

Uma das principais questões abordadas nos modelos encontrados na literatura refere-se à importância do respeito à cultura e aos padrões de trabalho de cada empresa. Esta questão deve ser observada objetivando-se que o modelo desenvolvido possa ser efetivamente implementado e incorpore melhorias ao processo de projeto. Além disto, os conteúdos apresentados no modelo devem ser flexíveis, possibilitando o perfeito ajuste com relação às estratégias e a cultura de cada empresa.

De acordo com ROMANO (2003) é importante que exista uma definição clara das atividades do processo, juntamente com a definição dos principais intervenientes envolvidos e seu grau de atuação em cada atividade, além do fluxo principal de informações. Deve-se atentar para a definição do grau de detalhe do modelo. Este não (workflow) definido e detalhado, que estabeleça as relações entre as disciplinas que participam do processo de projeto, do planejamento da obra, sua execução e avaliação pós-ocupação.

Procurou-se explicitar também as principais interfaces do processo de projeto com os demais processos da empresa relativos à execução de seus empreendimentos. Assim, em uma primeira etapa da pesquisa estabeleceu-se um diagnóstico do processo de projeto da instituição - que não é detalhado no presente trabalho, e encontra-se nas referências (CAMPOS, 2010) -, por meio de análise de documentos, acompanhamento de rotinas do processo e entrevistas com agentes.

A segunda etapa da pesquisa foi composta pela elaboração do Termo de Referência a partir do diagnóstico realizado na primeira etapa. Foi desenvolvido um mapeamento dos processos identificando todas as relações entre os intervenientes, definição de etapas do processo de projeto, definição de escopo, relações de precedência, validações, aprovações. 0 Termo de Referência desenvolvido apresenta um fluxo de atividades para o processo de projeto, propondo algumas inovações e mudanças na divisão do trabalho, bem como a identificação das principais informações do processo. Detalhes do procedimento metodológico são descritos em CAMPOS (2010). deve ser muito genérico, não permitindo transparência e eficácia, e por outro lado não deve ser muito detalhado, para que o mesmo não tenha difícil implementação em função do excesso de documentação criada. Ainda, a variabilidade intrínseca do processo deve ser respeitada.

Uma ferramenta adequada para a representação do processo é o fluxograma. É importante atentar para que estes não se tornem longos e não percam sua eficácia. Para isto, é necessária a subdivisão hierárquica do processo. Assim, deve ser definido um fluxograma geral do processo, e seu detalhamento, representado em fluxogramas específicos. Nestes devem ser definidas as relações de precedência entre as atividades, buscando possibilitar o planejamento do processo. Ainda, devem ser definidas as diferenças entre os níveis hierárquicos estabelecidos, sendo claramente diferenciadas 
etapas e atividades do processo, objetivando-se conferir mais transparência ao modelo.

A consideração de todas as disciplinas de projeto no desenvolvimento do modelo é essencial para possibilitar que o modelo incorpore a visão multidisciplinar daqueles que desenvolvem projetos. É necessário também para que possam ser validadas as informações constantes do modelo, para simplificar a sua implementação, pois os mesmos são engajados ao processo de mudança. A importância do papel do gerente de projeto deve ser enfatizada, estimulando-se também o envolvimento dos projetistas estrutural e de sistemas prediais desde as fases iniciais do processo, objetivando que os projetos sejam desenvolvidos de acordo com as especificidades de cada disciplina envolvida.

Pode ser estabelecido um modelo de documentação que seja adequado à empresa como um todo, possibilitando o desenvolvimento de documentos padronizados também para outros processos.

Finalmente, ao longo do modelo devem ser previstas aprovações de atividades e/ou etapas do processo, propiciando o controle e a melhoria do mesmo. Deve-se considerar que usualmente a aceitação da etapa anterior é condição para o início da próxima etapa do processo.

Por outro lado, além desses aspectos acima citados, o termo de referência tem que levar em conta a realidade da empresa na qual é feita a sua aplicação, sobretudo levando em conta alguns aspectos, dos quais se destacam:

a) em primeiro lugar, o fato de que, por se tratar de uma instituição pública, a contratação dos projetos é regida pela Lei das Licitações, tornando-se necessária a observância de uma série de requisitos legais que, se por um lado garantem a lisura e a transparência na contratação dos projetos, por outro lado implicam em limitações por vezes graves e limitação do poder de compra do órgão contratante.

b) Em segundo lugar, o fato de que em grande parte dos casos os projetos referem-se a requalificação e reforma de agências da instituição; com frequência são obras de pequeno porte e que tem um ciclo de desenvolvimento reduzido (por vezes, poucos meses), o que implica em uma necessária agilidade no desenvolvimento dos projetos. Isso impacta no termo de referência para a contratação e desenvolvimento dos projetos, na medida em que esse termo tem de ser suficientemente simples para ser aplicado imediatamente pelas empresas contratadas, mais ainda levando em conta o fato de que dificilmente se concretizará uma parceria entre a empresa pública contratante eas empresas contratadas, que permita uma evolução no uso desse termo de referência, ou seja, a cada novo contrato é provável que atuem empresas diferentes.

Através da consideração destas diretrizes, podem ser desenvolvidos modelos que apresentem melhorias no processo de projeto, e que descrevam as ações gerenciais necessárias para seu estabelecimento como, por exemplo, a definição de planejamento, retroalimentação e a melhoria contínua do processo.

\subsection{Desenvolvimento do Modelo}

0 termo de referência para o desenvolvimento dos projetos consta de:

a) um Plano sumário, que estabelece diretrizes gerais para o desenvolvimento dos projetos;

b) uma Declaração de escopo, na qual são definidas as macro etapas do processo de projeto, de forma específica para cada empreendimento considerado;

c) uma Lista de atividades para cada etapa do processo de projeto;

d) um Cronograma preliminar, que leva em conta as peculiaridades de cada empreendimento e,

e) um Checklist contendo tarefas e saídas para o projeto arquitetônico, como comentado anteriormente.

Inicialmente definiu-se o plano sumário dos projetos a serem contratados. Neste plano sumário foram definidos o objetivo geral, as etapas do processo de projeto e as diretrizes a serem seguidas durante todo o processo.

O plano sumário considera uma peculiaridade do processo de projeto relativamente comum em instituições públicas: $o$ fato de que o empreendimento conta com um supervisor interno dos projetos (coordenador interno) e um coordenador externo, frequentemente um arquiteto, que tem a função de supervisionar o desenvolvimento dos projetos, definir as soluções para as interfaces entre projetos, os sistemas construtivos, etc. Ou seja, tem de ficar delineadas as funções de coordenação interna e coordenação externa. Leva-se em conta ainda o fato de que na instituição estudada a coordenação de projetos não é uma função institucionalizada, e, portanto não existem procedimentos ou diretrizes que regulem a função coordenação, razão pela qual define-se 
esse plano sumário de projeto. Em síntese, o plano sumário define as responsabilidades do coordenador interno da instituição e do coordenador externo, as responsabilidades legais e gerenciais das empresas contratadas e os mecanismos de relacionamento entre a equipe interna e a equipe externa no processo de projeto.

$\mathrm{Na}$ sequência define-se o escopo geral do processo de projeto definindo suas etapas e o objetivo a ser alcançado pelas especialidades nestas etapas. Após a definição do escopo geral desenvolveu-se a lista de atividades a serem realizadas pelas especialidades em cada etapa.

No intuito de induzir a uma simultaneidade na elaboração dos projetos, para todos os agentes envolvidos, foram desenvolvidos os fluxogramas de seqüenciamento do processo de projeto. 0 fluxograma do escopo geral determina as etapas do processo e as validações a serem realizadas pelos agentes da instituição no final de cada etapa. Por sua vez, os fluxogramas das etapas organizam a seqüência de desenvolvimento das atividades das especialidades, priorizando 0 conceito de projeto simultâneo comentado anteriormente. Pretende-se que através dos fluxogramas os agentes consigam pontuar sua participação dentro do processo e as relações de precedência e continuidade.

O cronograma preliminar fixa datas de inicio e fim de cada etapa, importantes para o gerenciamento de prazos.

No final do Termo de Referência apresenta-se o checklist de arquitetura que procura padronizar a entrega (deliverables) de cada etapa do processo. 0 checklist foi desenvolvido por etapas, conforme a lógica do Termo de Referência. Portanto, a cada etapa finalizada existe uma etapa do ckecklist a ser consultada. Optou-se por desenvolver somente o checklist da especialidade de Arquitetura pois, após a experimentação, será verificado a viabilidade deste formato de checklist para as outras especialidades. Por outro lado, esse projeto é condicionante dos demais e, de certa forma, é hierarquicamente superior às demais especialidades.

Na figura 1 representa-se, de forma esquemática, o termo desenvolvido.

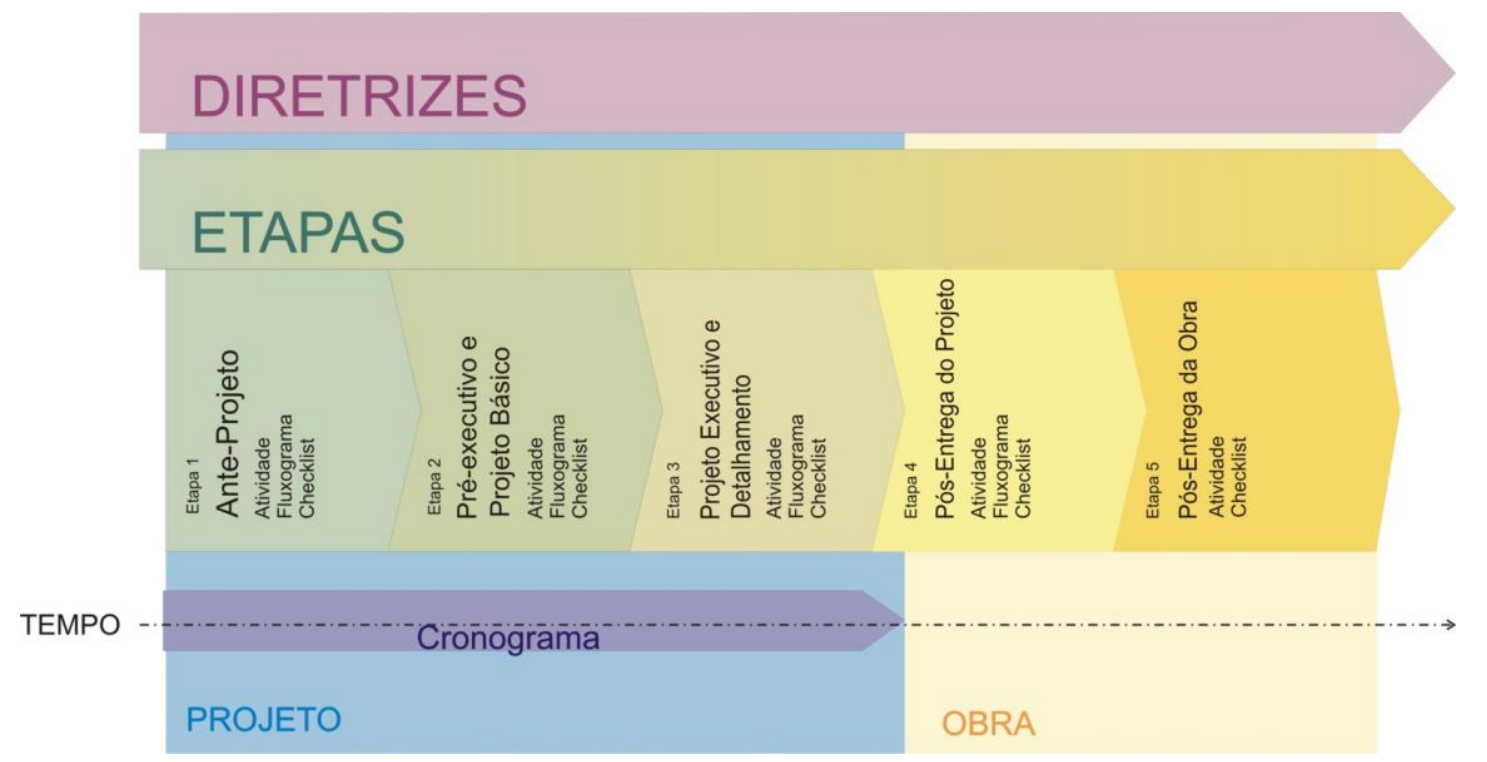

Figura 1: O Termo de Referência no contexto do desenvolvimento do processo de projeto.

Para o desenvolvimento da declaração do escopo geral do processo de projeto, na definição da lista de atividades, no desenvolvimento do fluxograma para o seqüenciamento do processo e no cronograma preliminar foram adotadas estruturas adaptadas referenciadas em ROMANO (2003), que apresenta um Modelo de Referência para o Gerenciamento do Processo de Projeto Integrado de Edificações (GPPIE). Ou seja, o presente modelo encontra sua principal referência no trabalho de ROMANO (2003). O modelo desenvolvido pela autora é dividido em Macrofases conforme pode ser verificado na figura 2. Estas Macrofases agrupam uma seqüência de etapas e atividades a serem realizadas para se alcançar o gerenciamento do processo de projeto integrado de edificações. Nesse contexto destaca-se a Macrofase definida pela autora como pré - projetação, que foi utilizada na presente pesquisa. Esta Macrofase corresponde ao planejamento do empreendimento através de uma abordagem 
sistemática - representação descritiva. Uma das principais atividades desta Macrofase é a organização do trabalho a ser realizado ao longo do processo do projeto.

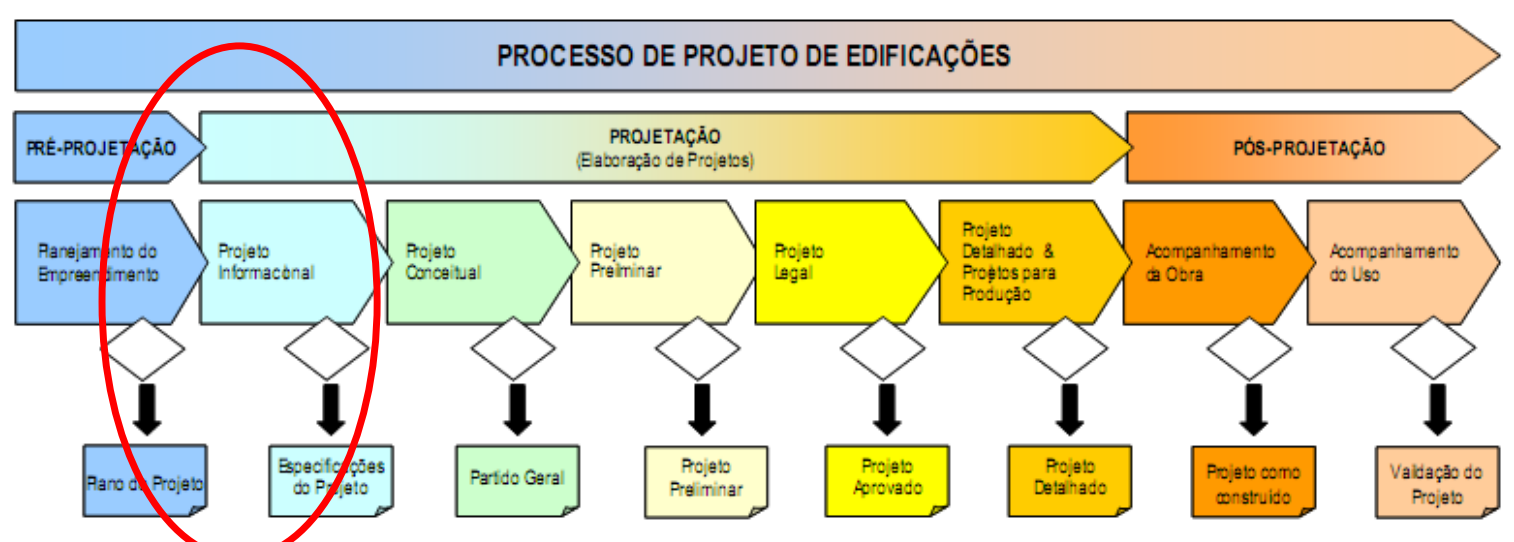

Figura 2: Representação gráfica das fases do processo de projeto de edificações- destaque para a Macrofase de pré-projetação. Fonte: Romano (2003)

“A representação descritiva do modelo de referência para o GPPIE é constituída de oito planilhas, cada uma representando uma fase do processo descrita através de sete elementos: entradas, atividades, tarefas, domínios, mecanismos, controles e saídas." ROMANO (2003).

A estrutura desenvolvida pode ser verificada em uma das planilhas retirada do trabalho da autora conforme tabela 1. Cada elemento desta estrutura possui uma finalidade: "as atividades e tarefas representam o trabalho a ser realizado. As entradas são as informações ou objetos físicos a serem processados ou transformados pela tarefa. Os mecanismos são os recursos físicos e/ou informações necessárias para a execução da tarefa (documentos, metodologias, técnicas,ferramentas). Os controles são as informações usadas para monitorar ou controlar a tarefa. E, as saídas são as informações ou objetos físicos processados ou transformados pela tarefa." ROMANO (2003). 
Tabela 1: Estrutura para representação do modelo de referência para o GPPIE. Fonte: Romano (2003).

\begin{tabular}{|c|c|c|c|c|c|}
\hline Entradas & Atividades & Tarefas & Mecanismos & Controles & Saídas \\
\hline \multirow{5}{*}{$\begin{array}{l}\text { Planejamento } \\
\text { de marketing } \\
\text { Plano } \\
\text { sumário do } \\
\text { projeto }\end{array}$} & \multirow{5}{*}{$\begin{array}{l}\text { Elaborar a } \\
\text { declaração } \\
\text { do escopo } \\
\text { do projeto }\end{array}$} & $\begin{array}{l}\text { Descrever as } \\
\text { saídas de cada } \\
\text { fase do projeto }\end{array}$ & $\begin{array}{l}\text { Conhecimento } \\
\text { em } \\
\text { gerenciamento } \\
\text { de tempo } \\
\text { Software de } \\
\text { gerenciamento } \\
\text { de projetos }\end{array}$ & $\begin{array}{l}\text { Plano } \\
\text { Estratégico de } \\
\text { negócio }\end{array}$ & \multirow{5}{*}{$\begin{array}{l}\text { Declaração } \\
\text { do escopo } \\
\text { do projeto }\end{array}$} \\
\hline & & $\begin{array}{l}\text { Definir os } \\
\text { objetivos do } \\
\text { projeto }\end{array}$ & $\begin{array}{l}\text { Análise custo/ } \\
\text { benefício }\end{array}$ & $\begin{array}{l}\text { Plano } \\
\text { estratégico de } \\
\text { produtos }\end{array}$ & \\
\hline & & $\begin{array}{l}\text { Identificar os } \\
\text { domínios de } \\
\text { conhecimento } \\
\text { necessários ao } \\
\text { projeto e suas } \\
\text { interdependênci } \\
\text { as }\end{array}$ & $\begin{array}{l}\text { Análise do tipo } \\
\text { de } \\
\text { empreendimen } \\
\text { to }\end{array}$ & $\begin{array}{l}\text { Planejamento de } \\
\text { marketing }\end{array}$ & \\
\hline & & $\begin{array}{l}\text { Definir a forma } \\
\text { de gerencia- } \\
\text { mento do } \\
\text { escopo do } \\
\text { projeto } \\
\text { (reavaliação/ } \\
\text { controle de } \\
\text { mudanças) }\end{array}$ & $\begin{array}{l}\text { Conhecimento } \\
\text { em gerencia- } \\
\text { mento de } \\
\text { escopo }\end{array}$ & \multirow[t]{2}{*}{$\begin{array}{l}\text { Plano } \\
\text { estratégico de } \\
\text { produtos }\end{array}$} & \\
\hline & & $\begin{array}{l}\text { Avaliar a } \\
\text { declaração do } \\
\text { escopo do } \\
\text { projeto }\end{array}$ & $\begin{array}{l}\text { Análise da } \\
\text { declaração do } \\
\text { escopo do } \\
\text { projeto }\end{array}$ & & \\
\hline
\end{tabular}

A representação descritiva do modelo de referência apresentado por ROMANO (2003) foi adaptada e simplificada para a realidade da instituição pesquisada, como indicado na Tabela 2. Nesta adaptação trabalhou-se com quatro elementos: entradas, atividades, tarefas e saídas.
Os elementos excluídos (domínios de conhecimento, mecanismos e controles) não foram considerados necessários, já que a instituição pesquisa não necessita de um modelo com nível de complexidade tão elevado quanto o apresentado pela autora. 
Tabela 2: Adaptação da estrutura para representação do modelo de referência para o GPPIE.

\begin{tabular}{|c|c|c|c|}
\hline Entrada & Atividade & Tarefa & Saída \\
\hline \multirow{4}{*}{$\begin{array}{l}\text { Plano Sumário } \\
\text { do Projeto }\end{array}$} & \multirow{4}{*}{$\begin{array}{l}\text { Elaborar a declaração } \\
\text { do escopo do projeto }\end{array}$} & $\begin{array}{l}\text { Descrever saídas de cada etapa } \\
\text { do projeto }\end{array}$ & \multirow{3}{*}{$\begin{array}{l}\text { Declaração do } \\
\text { escopo do } \\
\text { projeto }\end{array}$} \\
\hline & & Definir os objetivos do projeto & \\
\hline & & $\begin{array}{l}\text { Identificar os domínios de } \\
\text { conhecimento necessários ao } \\
\text { projeto e suas } \\
\text { interdependências }\end{array}$ & \\
\hline & & $\begin{array}{l}\text { Avaliar a declaração do escopo } \\
\text { do projeto }\end{array}$ & \\
\hline
\end{tabular}

\subsection{Declaração do escopo geral do processo de projeto - definição das etapas}

No modelo proposto, a declaração do escopo do projeto define as macro etapas do processo de projeto a serem seguidas pelos contratados e contratantes. Neste trabalho o escopo foi baseado nos Manuais de Escopo (desenvolvidos sob o patrocínio do SECOVI-SP), bem como na prática já adotada na instituição.

A tabela abaixo conduz a organização do escopo. Esta foi desenvolvida através da adaptação do modelo de referência para o GPPIE de ROMANO (2003), assim como as próximas três tabelas a serem apresentadas.A declaração do escopo geral do processo de projeto pode ser verificada em CAMPOS,(2010).

Tabela 3: Elaboração da declaração do escopo do projeto. Fonte: Adaptado de ROMANO, FV (2003)

\begin{tabular}{|c|c|c|c|}
\hline Entrada & Atividade & Tarefa & Saída \\
\hline \multirow{4}{*}{$\begin{array}{l}\text { Plano } \\
\text { Sumário do } \\
\text { Projeto }\end{array}$} & \multirow{4}{*}{$\begin{array}{l}\text { Elaborar a declaração } \\
\text { do escopo do projeto }\end{array}$} & $\begin{array}{l}\text { Descrever saídas de } \\
\text { cada etapa do projeto }\end{array}$ & \multirow{3}{*}{$\begin{array}{l}\text { Declaração do escopo } \\
\text { do projeto }\end{array}$} \\
\hline & & $\begin{array}{l}\text { Definir os objetivos do } \\
\text { projeto }\end{array}$ & \\
\hline & & $\begin{array}{l}\text { Identificar os domínios } \\
\text { de conhecimento } \\
\text { necessários ao projeto } \\
\text { e suas } \\
\text { interdependências }\end{array}$ & \\
\hline & & $\begin{array}{l}\text { Avaliar a declaração do } \\
\text { escopo do projeto }\end{array}$ & \\
\hline
\end{tabular}




\subsection{Definição da lista de atividades do processo de projeto por etapa}

A tabela abaixo conduz a definição da lista de atividades do projeto e foi baseada no modelo de referência para o GPPIE, nos Manuais de Escopo e na prática já adotada na instituição. A lista de atividades pode ser verificada em CAMPOS, (2010).

Tabela 4: Definição da lista de atividades do projeto. Fonte: Adaptado de ROMANO (2003)

\begin{tabular}{|l|l|l|l|}
\hline \multicolumn{1}{|c|}{ Entrada } & \multicolumn{1}{|c|}{ Atividade } & \multicolumn{1}{c|}{ Tarefa } & \multicolumn{1}{c|}{ Saída } \\
\hline \multirow{2}{*}{$\begin{array}{l}\text { Declaração do } \\
\text { Escopo do projeto }\end{array}$} & $\begin{array}{l}\text { Definir as atividades } \\
\text { do projeto }\end{array}$ & $\begin{array}{l}\text { Identificar as } \\
\text { atividades do projeto e } \\
\text { os principais eventos } \\
\text { (marcos) }\end{array}$ & $\begin{array}{l}\text { Lista das atividades do } \\
\text { projeto }\end{array}$ \\
\cline { 2 - 4 } & $\begin{array}{l}\text { Emitir a lista de } \\
\text { atividades do projeto }\end{array}$ & \\
\hline
\end{tabular}

\subsection{Sequenciamento do processo de projeto}

A tabela abaixo conduz o desenvolvimento do fluxograma de sequenciamento: do processo de projeto com suas etapas e lista de atividades do processo de projeto por etapa. Neste momento buscou-se trabalhar com a simultaneidade.

A tabela foi baseada no modelo de referência para o GPPIE, nos Manuais de Escopo e na prática já adotada na instituição.

Tabela 5: Sequenciamento das atividades do projeto. Fonte: Adaptado de ROMANO, (Tese, 2003)

\begin{tabular}{|c|c|c|c|}
\hline Entrada & Atividade & Tarefa & Saída \\
\hline \multirow{2}{*}{$\begin{array}{l}\text { Lista das } \\
\text { atividades do } \\
\text { projeto }\end{array}$} & \multirow{2}{*}{$\begin{array}{l}\text { Sequenciar as } \\
\text { atividades do } \\
\text { projeto }\end{array}$} & $\begin{array}{l}\text { Identificar as atividades } \\
\text { interdependentes }\end{array}$ & \multirow{2}{*}{$\begin{array}{l}\text { Seqüenciamento das } \\
\text { atividades do projeto } \\
\text { (fluxograma) }\end{array}$} \\
\hline & & $\begin{array}{l}\text { Elaborar o diagrama de } \\
\text { precedência das } \\
\text { atividades }\end{array}$ & \\
\hline
\end{tabular}

Primeiramente foi desenvolvimento um fluxograma que apresentasse o sequenciamento macro do processo de projeto - figura 19 e posteriormente os fluxogramas que apresentassem o sequenciamento da lista de atividades do processo de projeto por etapas figuras 3 e seguintes.

\subsection{Sequenciamento macro do processo de projeto e sequenciamento da lista de atividades do processo de projeto por etapa}

Nas figuras das próximas páginas serão demonstrados:

- $\quad$ fluxograma macro do processo de projeto, que demonstra o início e fim do processo e o sequenciamento das etapas e validações - figura 3 .

- $\quad 0$ fluxograma da etapa 1 , que demonstra o sequenciamento das atividades das diversas especialidades para o desenvolvimento do AnteProjeto - figura 4.

- $\quad$ Em sequência, o fluxograma da etapa 2,que demonstra o sequenciamento das atividades das diversas especialidades para o desenvolvimento dos projetos Pré-Executivo e Básico - figura 5.

- $\quad 0$ fluxograma da etapa 3, que demonstra o sequenciamento das atividades das diversas especialidades para o desenvolvimento dos projetos Executivos e de Detalhamento - figura 6. 
- $\quad$ Finalizando os fluxogramas, o fluxograma da etapa 4, que demonstra o sequenciamento das atividades das diversas especialidades na Pós-Entrega do Projeto.
- $\quad$ Na etapa 5, de Pós-entrega da obra, as atividades são realizadas sem interdependência, de acordo com a demanda. Portanto não há fluxograma para esta última etapa.

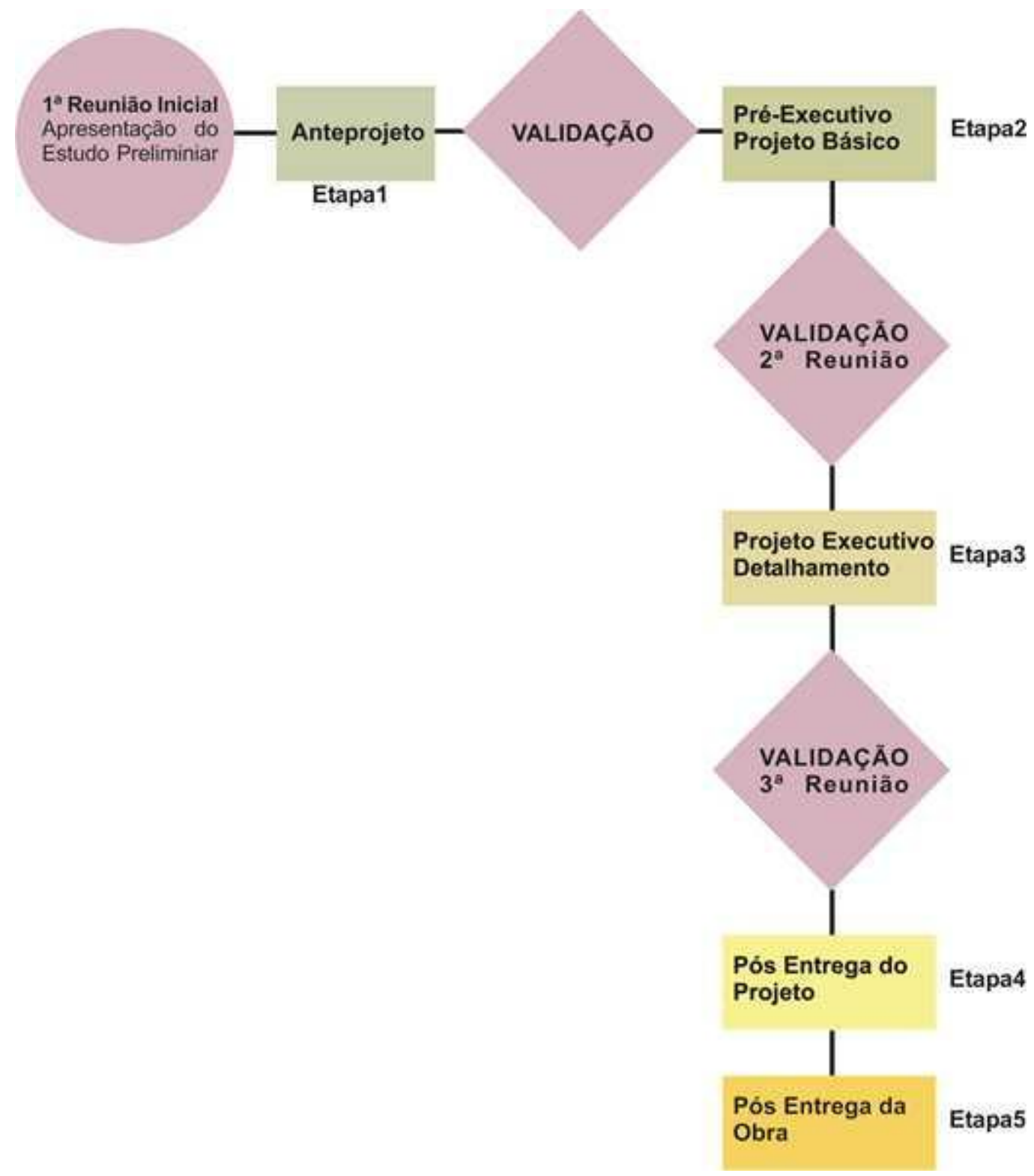

Figura 3: Sequenciamento macro do processo de projeto. 


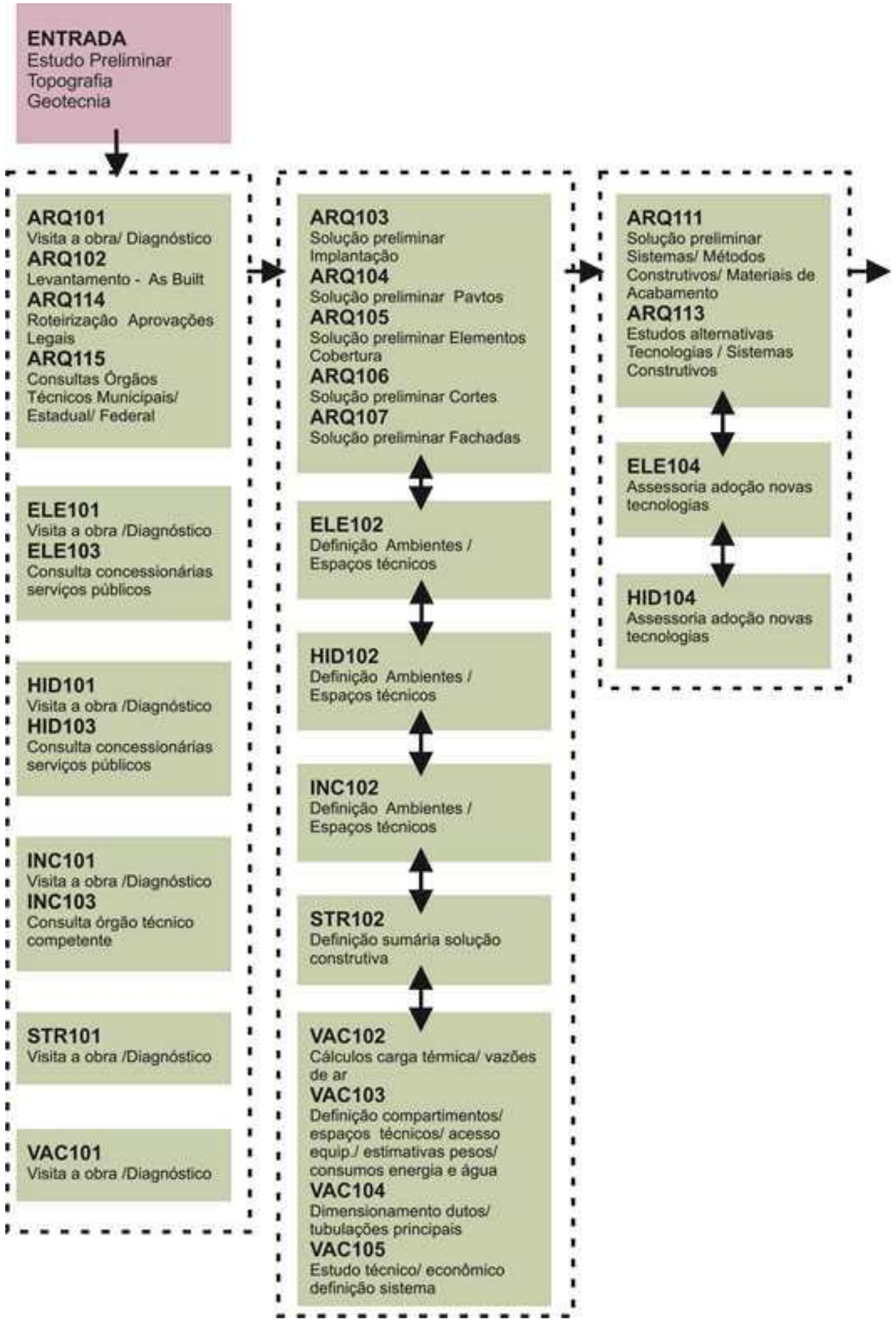

Figura 4: Sequenciamento da lista de atividades do processo de projeto - Etapa 1 


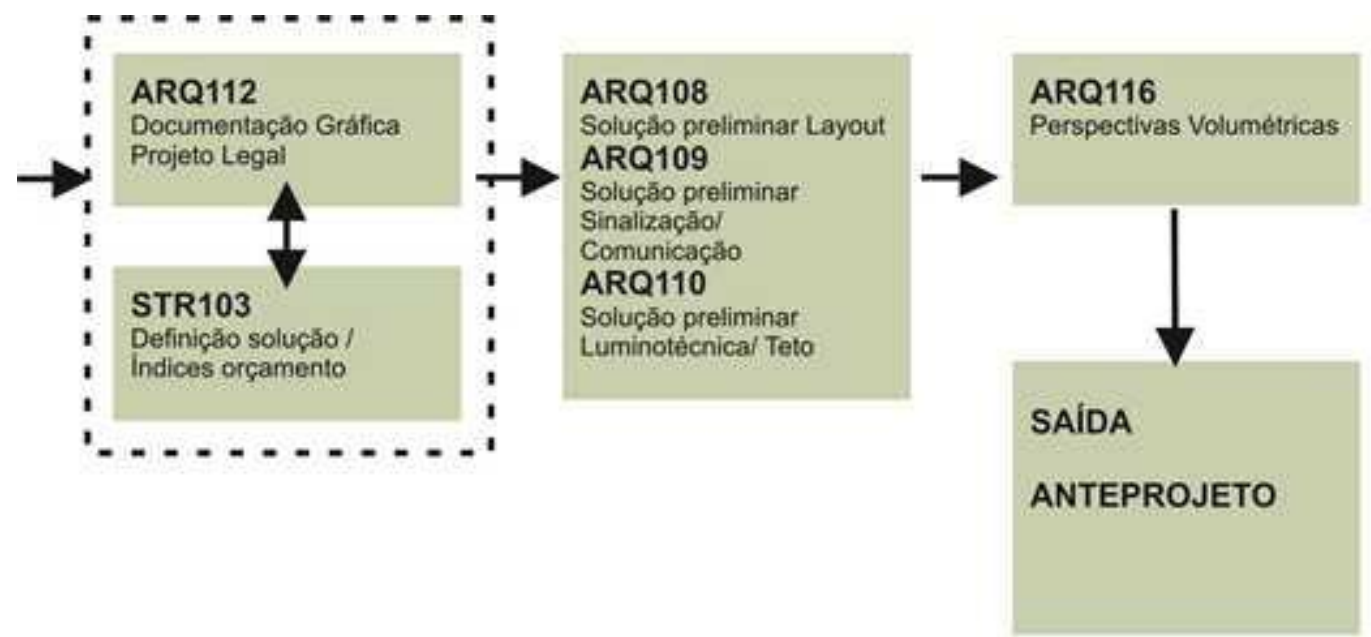

LEGENDA

Comunicação
Intensa
OProjeto pode ser
retornado ao anterior
parasaso

(Continuação daFigura 4) 


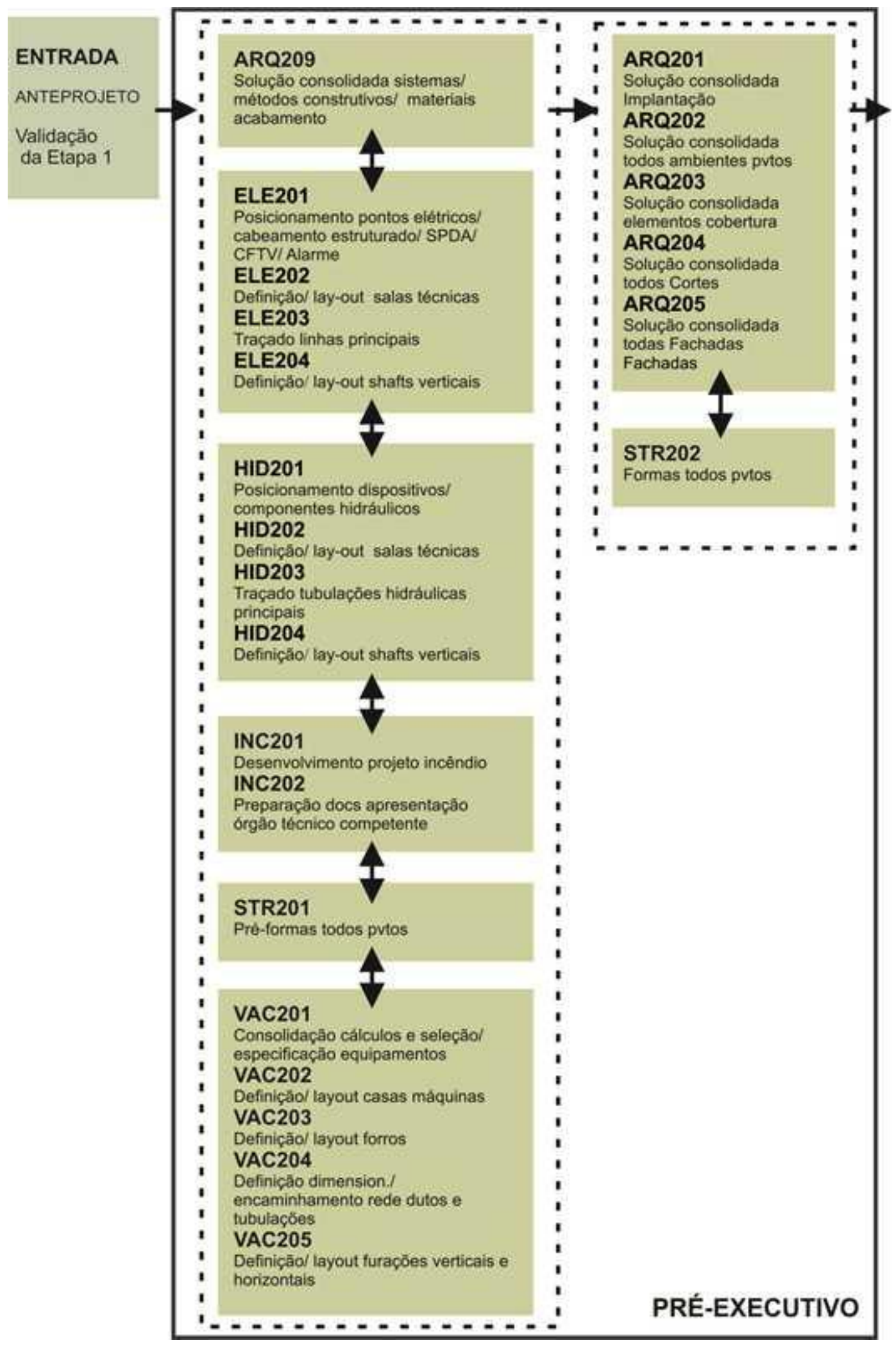

Figura 5: Sequenciamento da lista de atividades do processo de projeto - Etapa 2 


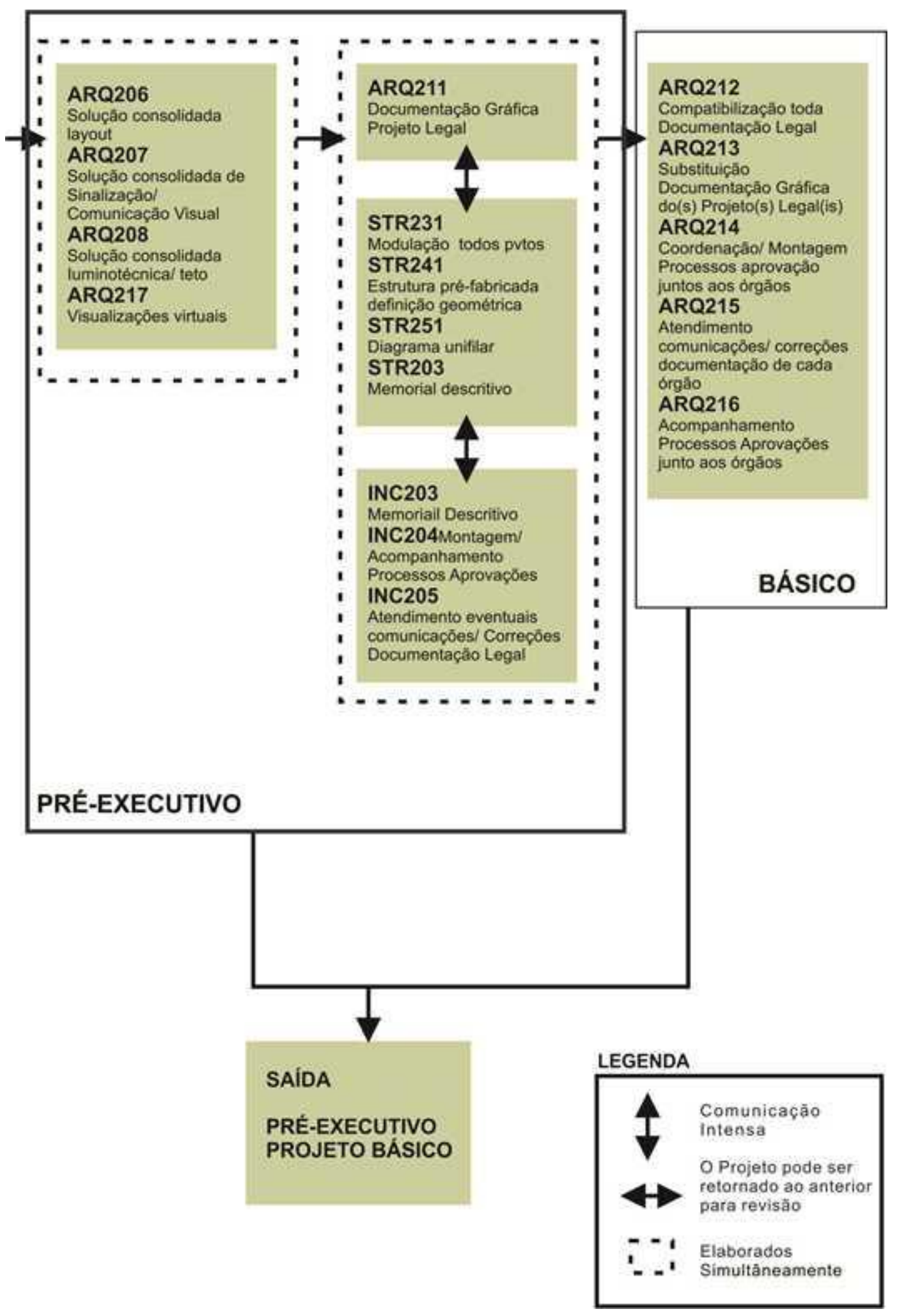

(Continuação daFigura 5.) 


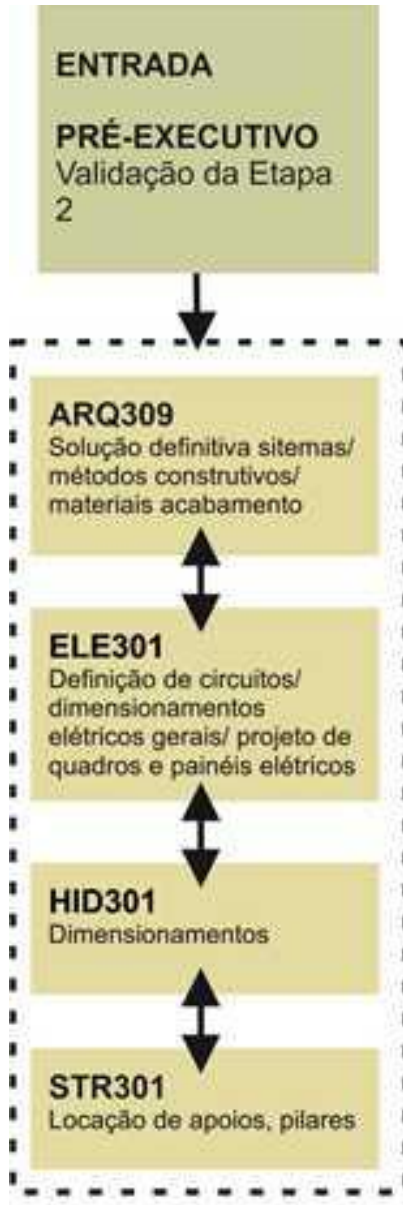

\section{STR302}

Forma Fundaçāo

STR303

Projeto elementos

estruturais fundaçăo

STR304

Projeto contençōes

internas e externas

STR305

Projeto estrutural formas:

armaçōes/ detaihes

STR306

Plano cimbramento

STR331

Projeto $1^{a}$ e $2^{a}$ filadas/

elevaça paredes

STR341

Projeto elementos pré.

moldados

STR351

Projeto estrutural unifilar

detalhes construtivos

insertos e chumbadores

STR308

Projeto laje estrutura

fundaçōes

STR309

Laje subpressāo

STR 310

Parede diafragma

STR311

Cortina atirantada

STR312

Projeto câmara

transformadora

STR313

Memorial descritivo

processo construtivo

estrutura

STR314

Projeto protensào

STR315

Projeto contençóes

provisórias

STR316

Projeto escoramento valas

STR317

Piso estrutural

STR318

Interferència construp̧ōes

existentes
ARQ302

Soluçăo definitiva todos

Ambientes/Pavimentos

ARQ303

Soluçăo definitiva sistemas

Coberturas

ARQ304

Soluçào dofinitiva Cortes

ARQ305

Solução definitiva todas

Fachadas

ARQ306

Soluça definitiva layout

ARQ307

Solução definitiva Sinalização

Comunicaclio Visual

ARQ308

Solução definitiva Projeto

Luminotécnica/ teto -

Detalhamento Forros

ARQ309

Soluçāo definitiva Métodos Construtivos/Materiais de

Acabamento

ARQ310

Detalhamento Áreas Molhadas

ARQ311

Detalhamento Escadas/

Rampas

ARQ312

Detalhamento Construtivo

Especifico (Horizontal/ Vertical)

\section{ARQ313}

Detalhamento Básico

Esquadrias/ Elementos de

Ferrol Aluminio/ Madeira e Vidro

\section{ARQ314}

Detalhamento Básico Muros

Divisa/ Piscinas/Elementos Água

ARQ315

Tabelas Acabamentos

ARQ316

Detalhamento

Pavimentaçóes/Pisos

ARQ317

Detalhamento Sistemas

Impermeabilizaçōes

ARQ318

Elevaçoes internas Paredes

Figura 6: Sequenciamento da lista de atividades do processo de projeto - Etapa 3 


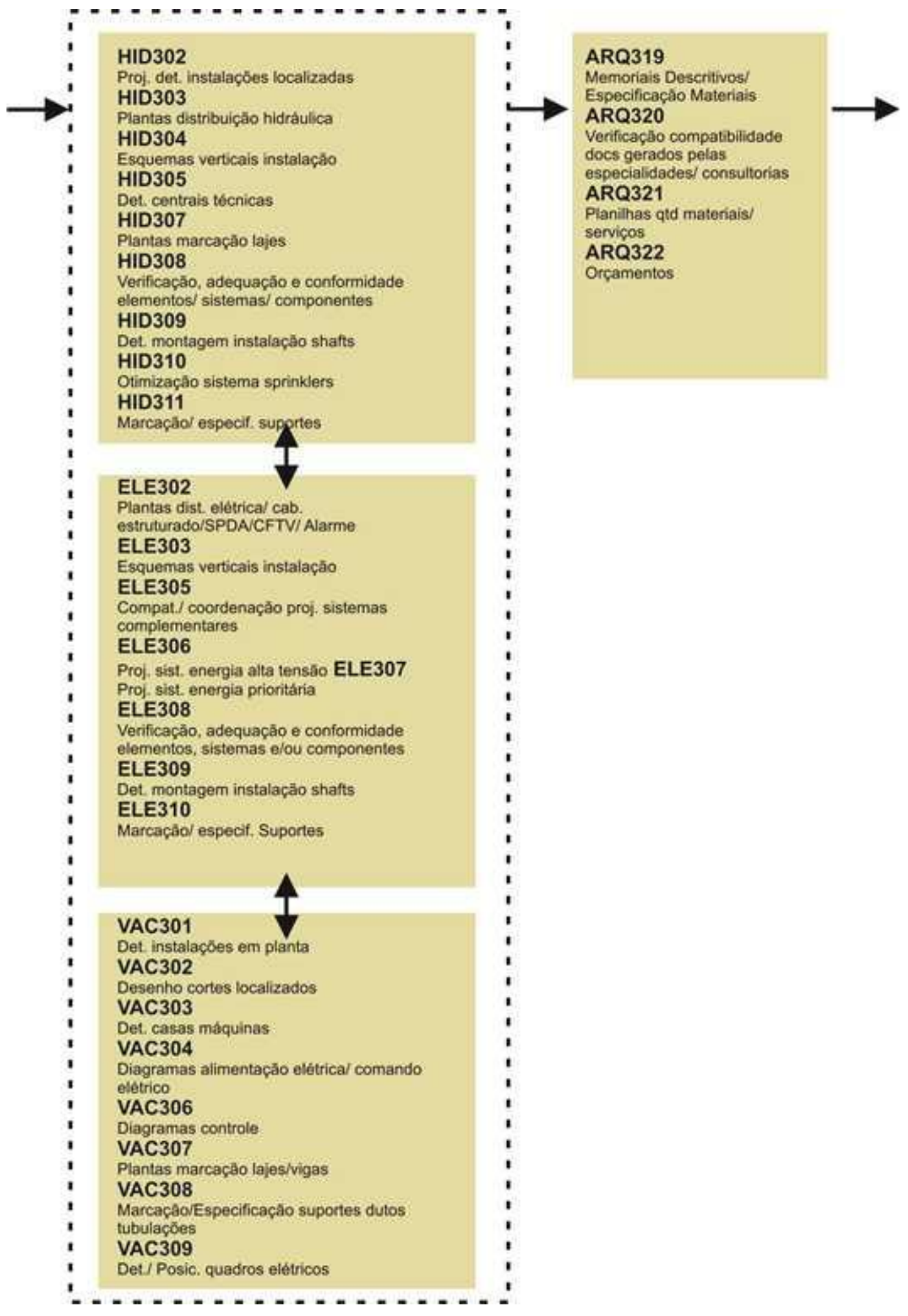

(Continuação da Figura6). 


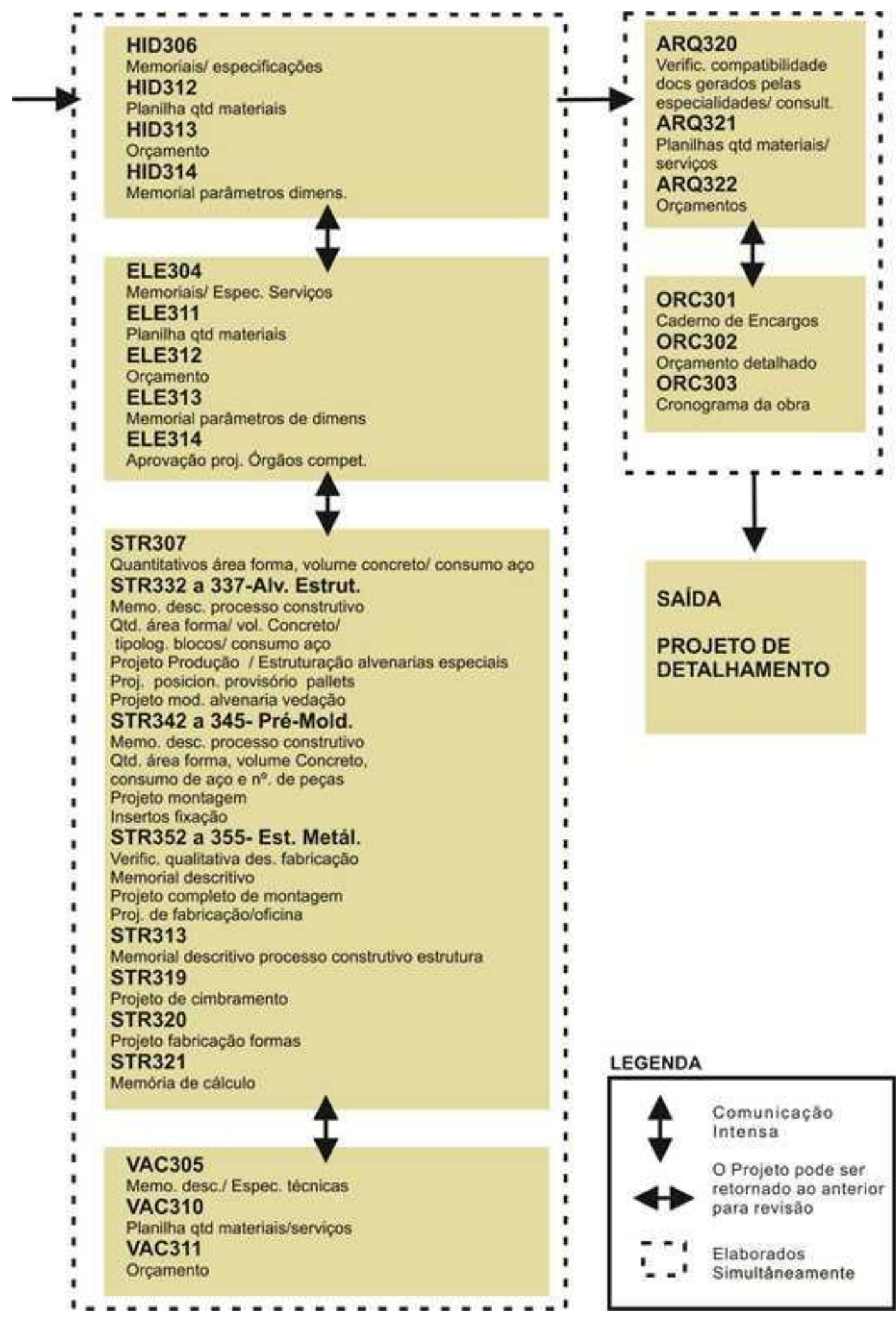

(Continuação da Figura6). 


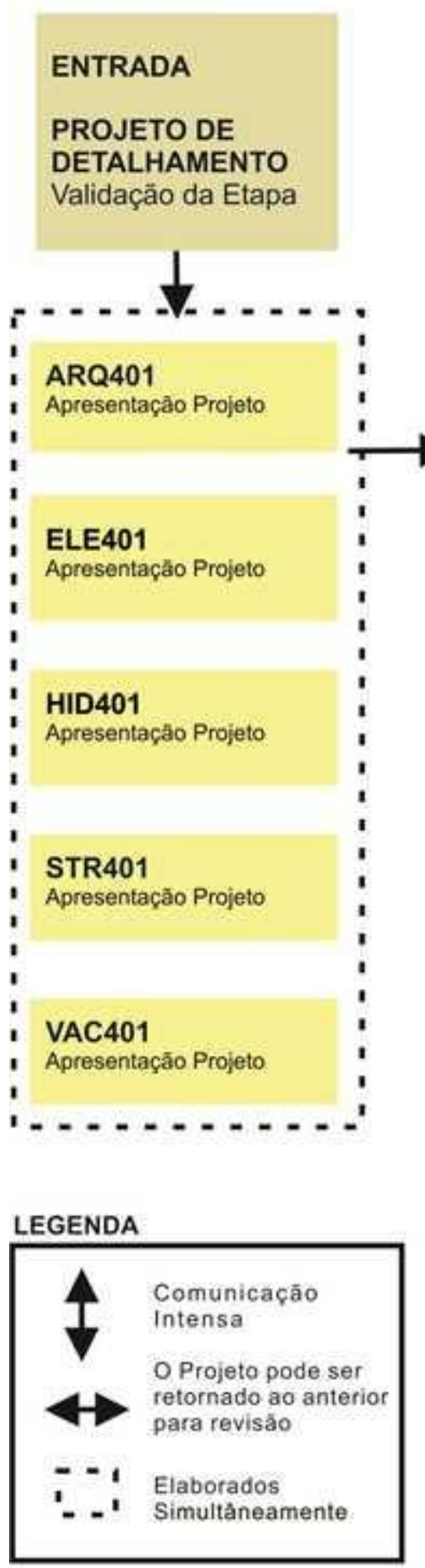

\section{ARQ402}

Esclarecimento Dúvidas

ARQ403

Acompanhamento Básico Obra

ARQ404

Análise Soluçōes Alternativas

ARQ405

Adaptaçăo/ Alteraçס̃es Projeto

ARQ406

Compat/Espec. Fornecedores

ELE402- Esclarecimento

ELE403 - Acompanhamento básico obra

ELE404 - Análise soluçōes alternativas

ELE405 - Alteraçōes projeto

ELE406 - Orientaçăo procedim, execuçao

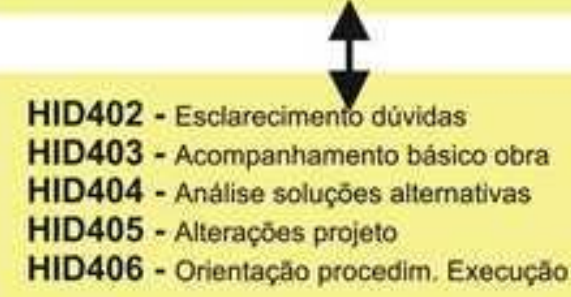

HID406 - Orientaçăo procedim. Execução

STR402 - Visitas técnicas/ Assistência obra

STR403 - Verific. estrutura/ relatório técnico

STR404 - Detalhamento reforço estrutural

STR405 - Correçầ vicios construtivos

VAC402

Esclarecimento dúvidas

VAC403

Análise soluçōes alternativas

VAC404

Alteraçōes projeto

VAC 405

Analise desenho detalh. $/$ planilhas equip. ofertados

VAC 406

Desenhos detalhamento obra

VAC 407

Orientaçăo procedimentos execução

VAC 408

Acomp. testes/ balanceamentos/ partida sistemas

Figura 7: Sequenciamento da lista de atividades do processo de projeto - Etapa 4 


\subsection{Cronograma preliminar do processo de projeto}

A tabela abaixo conduz a definição do cronograma do processo de projeto e foi baseada no modelo de referência para o GPPIE, nos Manuais de Escopo e na prática já adotada na instituição.

Tabela 6: Elaboração do cronograma preliminar do projeto. Fonte:Adaptado de ROMANO, Fabiane Vieira (Tese, 2003).

\begin{tabular}{|c|c|c|c|}
\hline Entrada & Atividade & Tarefa & Saída \\
\hline $\begin{array}{ll}\text { - } & \text { Lista das } \\
\text { atividades do } \\
\text { projeto }\end{array}$ & $\begin{array}{l}\text { Estimar a duração das } \\
\text { atividades }\end{array}$ & & $\begin{array}{l}\text { Estimativa de duração } \\
\text { das atividades }\end{array}$ \\
\hline $\begin{array}{ll}\text { - } & \text { Fluxograma } \\
\text { - } & \text { Estimativa de } \\
& \text { duração das } \\
& \text { atividades } \\
- & \text { Calendários } \\
\text { - } & \text { Folgas }\end{array}$ & $\begin{array}{l}\text { Desenvolver o } \\
\text { cronograma preliminar } \\
\text { do projeto }\end{array}$ & $\begin{array}{l}\text { Definir as datas de } \\
\text { início e fim do projeto. }\end{array}$ & $\begin{array}{l}\text { Cronograma } \\
\text { preliminar do projeto }\end{array}$ \\
\hline
\end{tabular}

Definiu-se como cronograma preliminar, porque suas definições podem mudar dependendo do escopo e de acordo com o andamento do desenvolvimento dos projetos. A estrutura de dados é indicada na figura abaixo.

Tabela 7: Cronograma preliminar do projeto.

\begin{tabular}{|l|l|l|}
\hline Etapas & $\begin{array}{l}\text { Prazo de execução de } \\
\text { cada etapa } \\
\text { (em dias corridos) }\end{array}$ & $\begin{array}{l}\text { Cronograma preliminar do } \\
\text { projeto } \\
\text { (data ou prazo a partir de uma } \\
\text { referência) }\end{array}$ \\
\hline Etapa 1: ante-projeto & & \\
\hline $\begin{array}{l}\text { Etapa 2: pré-executivo e projeto } \\
\text { básico }\end{array}$ & & \\
\hline $\begin{array}{l}\text { Etapa 3: projeto executivo e } \\
\text { detalhamento }\end{array}$ & & \\
\hline Etapa 4: pós-entrega do projeto & & \\
\hline Etapa 5: pós-entrega da obra & & \\
\hline
\end{tabular}

\subsection{Checklist para desenvolvimento de projetos de arquitetura}

O checklist procura padronizar a entrega de cada etapa do processo, conferindo uma maior qualidade e menos revisões por falta de informações. Ele foi desenvolvido conforme a lógica do Termo de Referência, ou seja, como o Termo de Referência é divido por etapas que são validadas, o checklist também foi desenvolvido por etapas. Portanto, a cada etapa finalizada existe uma etapa do ckecklist a ser consultado.
Optou-se por desenvolver somente o checklist da especialidade de Arquitetura, pois, após a experimentação, será verificado a viabilidade deste formato de checklist para as outras especialidades.

0 checklist desenvolvido para ser parte integrante do Termo de Referência encontra-se em CAMPOS, (2010), e por sua extensão, não será detalhadamente apresentado nesse texto 


\section{ANÁLISE DE RESULTADOS}

0 Termo de Referência foi implementado na contratação de projetos em dois tipos de reformas de agências da instituição:

Implementação 1 - Agência A: Implantação de nova Agência em edifício construído por um investidor exclusivamente para a instituição. Após o término da obra pelo investidor a instituição inicia os projetos para implantação da Agência.

Implementação 2 - Agência B: Reforma para adequação do espaço de uma agência existente, em edifício da própria instituição.

As empresas tiveram dificuldade em fornecer uma proposta para um escopo de serviços mais detalhado. A diferença nos preços fornecidos pelos escritórios foi grande, o que normalmente não acontecia com solicitações onde o escopo não era tão explicitado. Deve-se ao fato de que algumas empresas entregavam os projetos com um escopo, que entendiam ser suficiente, e aguardavam que os agentes da instituição cobrassem revisões ou novas pranchas. Novas solicitações geravam aditivos contratuais, pois os itens faltantes não estavam claramente contemplados no escopo inicial da solicitação de proposta.

As empresas vencedoras da concorrência pública demonstraram dificuldades em se adequar na entrega dos trabalhos conforme o checklist, considerando alguns itens excessivos. Entendemos esta dificuldade por serem os primeiros trabalhos realizados através do termo de referência.

Na segunda implementação foi solicitado que os trabalhos fossem conferidos no final de cada etapa, de acordo com o checklist, mesmo assim manteve-se uma quantidade significativa de erros e/ ou ausência de informações com na primeira implementação. Nas duas implementações o tempo gasto pelo agente da instituição na conferência do projeto foi potencializado através do checklist. Verificou-se que o uso do checklist é positivo e deve ser desenvolvido para as outras especialidades além da de arquitetura.

As validações obtiveram a eficácia esperada. A cada validação os agentes da instituição alcançaram uma visão ampliada do trabalho realizado, tendo a possibilidade de verificar pontos chaves de projeto ou sugerir novas proposta antes que o trabalho estivesse mais desenvolvido e atingisse outras especialidades.

Em nenhuma das implementações o prazo foi respeitado. Os agentes da instituição tiveram dificuldades de responder às demandas dentro do prazo necessário devido ao acúmulo de serviços internos. Ponderou-se que o cronograma deve prever um prazo maior para a validação dos agentes da instituição.

As reuniões impostas no fluxograma possibilitaram considerar de forma antecipada e global as repercussões das decisões de projeto e tornar possível uma maior colaboração entre os agentes principais aumentando os benefícios durante o processo, diminuindo as incompatibilidades e melhorando a qualidade do produto final. Apesar do fluxograma geral do processo de projeto sugerir três reuniões em etapas definidas, nem sempre elas aconteceram na mesma ordem ou quantidade ou com todos os agentes envolvidos.

Considera-se que o Termo de Referência proposto atingiu parte de seus objetivos ao alcançar a participação efetiva de vários intervenientes e o início de um desenvolvimento integrado e simultâneo. 0 termo por si só não conseguiu equacionar questões culturais para sua implantação. Notou-se que a primeira, e talvez a maior, barreira a ser transposta é a cultura técnico-organizacional dos agentes da própria instituição. A maioria dos agentes não está disposta a mudar a forma de gerenciar e contratar projetos, pois não vislumbra melhorias em um espaço curto de tempo.

Não houve tempo hábil para verificar nas Etapas 4 e 5 os ganhos advindos dessa nova forma de trabalho. Supõe-se que a construtibilidade e manutenabilidade dos espaços propostos serão maiores, pois, como citado anteriormente, todas as disciplinas tiveram uma maior participação nas decisões projetuais através das reuniões e validações.

Como melhoria para uma terceira implementação incluiu-se nos fluxogramas a descrição de cada atividade. Esta inclusão teve como pretensão proporcionar um entendimento geral de cada etapa em uma única imagem, facilitando a leitura dos agentes. Percebeu-se que simplificando o Termo de Referência será alcançado um maior entendimento e em conseqüência o uso efetivo. 


\section{CONCLUSÃO}

Pesquisas em processo de projeto na construção civil que se desenvolveram nos últimos dez anos têm mostrado que a parceria entre atividades produtivas e universidade é capaz de promover a melhoria contínua do setor. Nesse contexto, vale ressaltar a formação de profissionais em nível de pós-graduação e os seus desdobramentos em termos das melhorias na integração dos projetos e projeto-produção.

As contribuições desta pesquisa situam-se no âmbito da criação de mecanismos mais efetivos para a contratação de projetos. Com referência nas idéias do "Projeto Simultâneo" (FABRICIO, 2002) e em uma proposta mais ampla (ROMANO, 2003), a criação e aplicação de um termo de referência para o gerenciamento de projetos proporcionaram avanços significativos para a instituição pública pesquisada.

Fundamentada nas experiências extraídas da aplicação do Termo de Referência nos processos pesquisados, pode-se verificar que é possível aplicar a modelagem em acordo com princípios do projeto simultâneo. É importante que sejam observadas as diretrizes do termo proposto, sobretudo em relação à simultaneidade das atividades, interatividade das equipes e gestão eficiente do processo de projeto.

Nessa direção, destacam-se a melhoria das relações entre contratante e contratada devido à definição mais clara do escopo dos serviços, a obtenção de maior eficiência do processo de projeto em função das reduções de prazos contratuais e dos retrabalhos e a integração entre projetistas e executores dos serviços pela introdução da nova metodologia.

Percebe-se que é necessário, para a consolidação desta proposta na instituição, adotar medidas de cunho mais estratégico com a alteração da própria cultura técnico-organizacional. Ainda neste pensamento de aplicabilidade, verificou-se que a simplicidade é importante para o uso efetivo do termo.

\section{REFERÊNCIAS BIBLIOGRÁFICAS}

ANDERY, Paulo R. P, ARANTES, Eduardo Marques, VIEIRA, Maria da Penha. Experiências em torno à Implementação de Sistemas de Gestão da Qualidade em Empresas de Projeto. In: IV Workshop Brasileiro de Gestão do Processo de Projeto na Construção do Edifício. Anais. Rio de Janeiro, RJ, 2004.

ASBEA. Manuais de escopo das áreas dos projetos de: Arquitetura e Urbanismo, Estrutura, Sistemas Elétricos, Sistemas Hidráulicos e Ar condicionado e Ventilação. 2009. Disponível em < http://www.manuaisdeescopo.com.br>.Acessado em: 01/02/2009.

ASBEA (Associação Brasileira de escritórios de Arquitetura). Manual de Contratação de Serviços de Arquitetura e Urbanismo. Ed. PINI, São Paulo, 1992, 107 p.

CAMPOS, Cíntia. 0. Termo de Referência para o Gerenciamento de Projetos Integrados em uma Instituição Pública. Dissertação (Mestrado em Construção Civil). Escola de Engenharia, Universidade Federal de Minas Gerais, 2010.

FABRICIO, Márcio Minto. Projeto Simultâneo na construção de edifícios. Tese de Doutorado, Escola Politécnica, Universidade de São Paulo, 2002, 329p.

MELHADO, S. B. Qualidade do Projeto na Construção de Edifícios: Aplicação ao caso das empresas de incorporação e construção. Tese de Doutorado, Escola politécnica da Universidade de São Paulo, 1994, $277 p$.

MELHADO, S. B. coord.; SOUZA, Ana Lúcia Rocha de; FONTENELLE, Eduardo; AQUINO, Janayna Patrícia Rezende de; GRILO, Leonardo Melhorato; FRANCO, Luiz Sérgio; MESQUITA Maria Julia; DUEÑAS PEÑA, Monserrat; FABRICIO, Márcio Minto; OLIVEIRA, Otávio José de. Coordenação de projetos de edificações. São Paulo: 0 Nome da Rosa, 2005. Cap. 4, p. 71-85.

MELHADO, S. O plano da qualidade dos empreendimentos e a engenharia simultânea na construção de edifícios. Encontro Nacional de Engenharia de Produção - ENEGEP, 19: Anais (CD-ROM). Rio de Janeiro, UFRJ/ABEPRO, 01-04 novembro/1999

OLIVEIRA, M. Um método para a obtenção de indicadores visando a tomada de decisão na etapa de concepção do processo construtivo: a percepção dos principais intervenientes. Tese (Doutorado) PPGA/UFRGS, Porto Alegre, 1999. 
OWEN, R., AMOR, R., PALMER, M., DICKINSON, J., CLYDE, B., TATUM, A. PRINS, M, KIVINIEMI, A, EAST, B. Challenges for integrated design and delivery solutions.Architectural Engineering and Design Management, vol. 6, pp. 232-240, 2010.

PRINS, M. e OWEN, R. Integrated design and delivery solutions.Architectural Engineering and Design Management, vol 6, pp. 227-231, 2010.

ROMANO, F. V. Modelo de referência para o Gerenciamento do Processo de Projeto Integrado de Edificações. Tese de Doutorado, Universidade Federal de Santa Catarina, 2003, 381p

SOUZA, R. Metodologia para desenvolvimento e implantação de sistemas de gestão da qualidade em empresas construtoras de pequeno e médio porte. Tese de doutorado, Escola Politécnica da Universidade de São Paulo. Departamento de Engenharia de Construção Civil e Urbana, São Paulo, 1997.

SCPD - Society of Concurrent Product Development.<<http:// www.scpdnet.org/>> acessado em 01/02/2009.

TZORTZOPOULOS, P. Contribuições para o Desenvolvimento de um Modelo do Processo de Projeto de Edificações em Empresas Construtoras Incorporadoras de Pequeno Porte. Dissertação de Mestrado Universidade Federal do Rio Grande do Sul, 1999, 163p.

VARGAS, Ricardo Viana. Gerenciamento de projetos: estabelecendo diferenciais competitivos. Rio de Janeiro, RJ, Brasport, 2000

\section{DADOS DOS AUTORES}

(i) Professor do Departamento de Engenharia de Materiais e Construção da Universidade Federal de Minas Gerais| Brasil.

(ii) Arquiteta, Sócia Titular da Lado A Arquitetura| Brasil

(iii) Professor Associado da Escola de Engenharia da Universidade Federal de Minas Gerais| Brasil. 